\title{
The Role of HDlive Technology in Obstetrics and Gynecology, Present and Future
}

${ }^{1}$ Mihaela Grigore, ${ }^{2}$ Camelia Cojocaru, ${ }^{3}$ Tudor Lazar

\begin{abstract}
Imaging techniques have continually evolved during the last few decades to improve diagnosis in obstetrics and gynecology. Developed more than 15 years ago, three-dimensional (3D) ultrasound has been widely used in clinical practice during the last decade, and its use continues to grow as researchers explore innovative new applications. High definition live (HDlive) ultrasound (US) is a novel ultrasound technology that improves both 3D and four-dimensional (4D) ultrasound images. This technology can mainly be used to study normal and pathologic embryonic and fetal development. HDlive could be important to perinatal research and could provide a better understanding of the development of the early embryo and fetus. Because of the natural pictures of the fetus that it provides, HDlive could be beneficial for increasing the fetal-maternal bonding, an important factor for healthy behavior during the pregnancy. In gynecology, HDlive could be useful in providing a better image of the adnexal pathology or coronal plane of the uterus. Although its advantages need to be further explored, in our opinion, HDlive is an innovative technique and a useful tool with applications both in obstetrics and gynecology.
\end{abstract}

Keywords: Three-dimensional, Four-dimensional, Ultrasound, Pregnancy, HDlive ultrasound, Fetal-maternal bonding.

How to cite this article: Grigore M, Cojocaru C, Lazar T. The Role of HDlive Technology in Obstetrics and Gynecology, Present and Future. Donald School J Ultrasound Obstet Gynecol 2014;8(3):234-238.

\section{Source of support: Nil}

Conflict of interest: None

\section{INTRODUCTION}

In recent years, imaging techniques have progressively evolved. Development in obstetrics and gynecologic imaging have contributed to improved diagnosis and refined management. Currently, ultrasound is a mandatory tool both in obstetrical and gynecological practice. Three-dimensional

\footnotetext{
${ }^{1-3}$ Consultant

${ }^{1,3}$ Department of Obstetrics and Gynecology, University of Medicine and Pharmacy 'Grigore T Popa', Iasi, Romania

${ }^{2}$ Department of Obstetrics and Gynecology, Medis Medical Centre, Iasi, Romania

Corresponding Author: Mihaela Grigore, Consultant Department of Obstetrics and Gynecology, University of Medicine and Pharmacy 'Grigore T Popa', Str Universitatii 16, Iasi-700115, Romania, Phone: +40-744438024, Fax: +40-232221516 e-mail: mihaela.grigore@edr.ro
}

(3D) and four-dimensional (4D) ultrasound were first demonstrated nearly 15 years ago, but are becoming a clinical reality only now. ${ }^{1}$ The 3D transducers take several hundreds or thousands of two-dimensional (2D) ultrasound images over a short $\left(30-40^{\circ}\right)$ arc. These images are then transferred to a computer that integrates them into a single image. The first generation of 3D ultrasound lacked the capability to reconstruct images rapidly and with high resolution. These limitations could explain why the method was not very popular initially.

With current clinically available equipment, 3D sonographic reconstruction is fast, with high resolution, giving ultrasound the ability to image in real time. ${ }^{2}$ Also, 3D ultrasound allows volume data to be stored and manipulated long after the patient has left the examination room. Storage of a single volume of data is easy and quick, yet the stored volume permits interpretation of the scanned region in multiple planes.

Both 3D and 4D ultrasound have improved our knowledge regarding the development of the embryo and fetus and of a great number of fetal anomalies. ${ }^{3}$ In addition, 3D ultrasound has proved to be beneficial not only for obstetrics, but also for gynecology. To date, studies focusing on the added value of 3D capabilities compared to 2D ultrasound have shown that $3 \mathrm{D}$ volume sonography provides important diagnostic information for gynecologic evaluation of uterine duplication anomalies and for optimal evaluation of the uterine cavity. ${ }^{4,5}$

Image quality is extremely important for depicting with clarity of the normal or abnormal pictures both in obstetrics and gynecology. Clearer images and elimination of redundant structures and artifacts allow better understanding of the studied structures. The latest achievement in the field of $3 \mathrm{D} / 4 \mathrm{D}$ ultrasound is the high definition live (HDlive) technology. This technology is a novel ultrasound technique that improves the $3 \mathrm{D} / 4 \mathrm{D}$ images. HDlive uses an adjustable light source and software that calculates the propagation of light through surface structures in relation to the light direction. ${ }^{6}$ The virtual light source produces selective illumination, and the respective shadows are created by the structures where the light is reflected. ${ }^{7}$ This combination of light and shadows increases depth perception and produces remarkable images that are more natural than those obtained with classic 3D ultrasound. The virtual light can be placed 
in the front, back, or lateral sides, where viewing is desired until the best image is achieved. ${ }^{7}$ A great advantage is that the soft can be applied to all images stored in the machine's memory.

In obstetrical ultrasound, HDlive could be used during all three trimesters of pregnancy. The images obtained with HDlive in the first trimester of pregnancy are very impressive for both parents and their relatives. The images closely resemble those from anatomy atlases or scientific documentaries (Figs 1A and B). The introduction of 3D/4D sonography in the first trimester of pregnancy has resulted in remarkable progress in sonographic visualization of early embryos and fetuses and in the development of the 3D sonoembryology. ${ }^{7}$ HDlive assesses both structural and functional developments in the first trimester of pregnancy with greater reliably than 2D

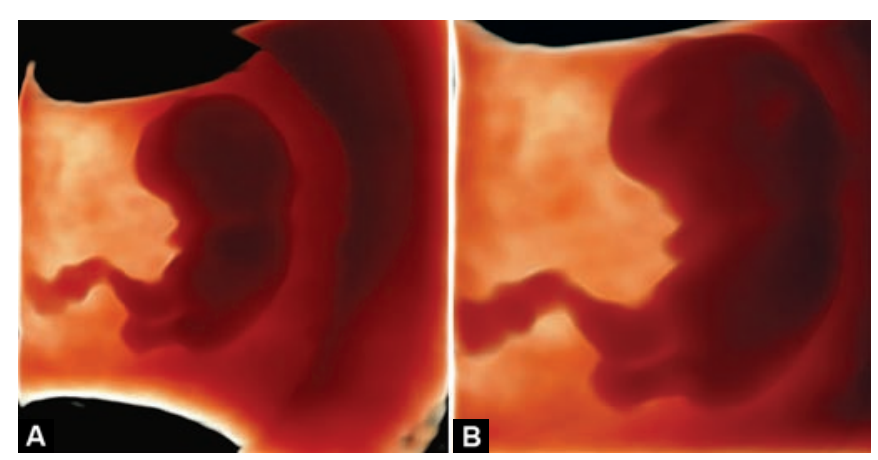

Figs 1A and B: HDlive at 8 weeks of amenorrhea. The light is positioned behind the embryo and translucency effect is obtained ultrasound. Figures 2 to 4 are several images of first trimester embryos and fetuses examined with HDlive technology (see Figs 2 to 4). The ability to visualize fetal hands, fingers, feet, and toes is better with volumetric ultrasound than 2D ultrasound. $^{3}$ The software enables visualization of the same picture with different light and shadows.

HDlive and 3D ultrasound are important tools in the diagnosis of some fetal anomalies. Hata et al proved the superiority of 3D ultrasound compared to 2D ultrasound in the assessment of the surface of anatomical structures (face, hand, and foot). They concluded that 3D ultrasound was a promising technique in assessing and detecting abnormalities in embryonic and early fetal development during the first trimester of gestation. ${ }^{8}$ HDlive will likely have its own contribution to the development of this field.

Some limitations of HDlive include the reduced image quality that can occur with embryonic or maternal movement and surface rendering of the embryo depends on the presence of enough amniotic fluid around the embryo. ${ }^{9}$ Another limitation is the distance of the embryo from the uterine wall and the curvature of the gestational sac. ${ }^{8}$

Visualization of the fetal face has become one of the main applications of 3D ultrasound scanning. Sometimes, the fetal position or the conditions of the exploration prevent appropriate slices being obtained in the 2D examination. In these cases, with appropriate rotations and translations, it is possible to move through the $3 \mathrm{D}$ volume until the target plane
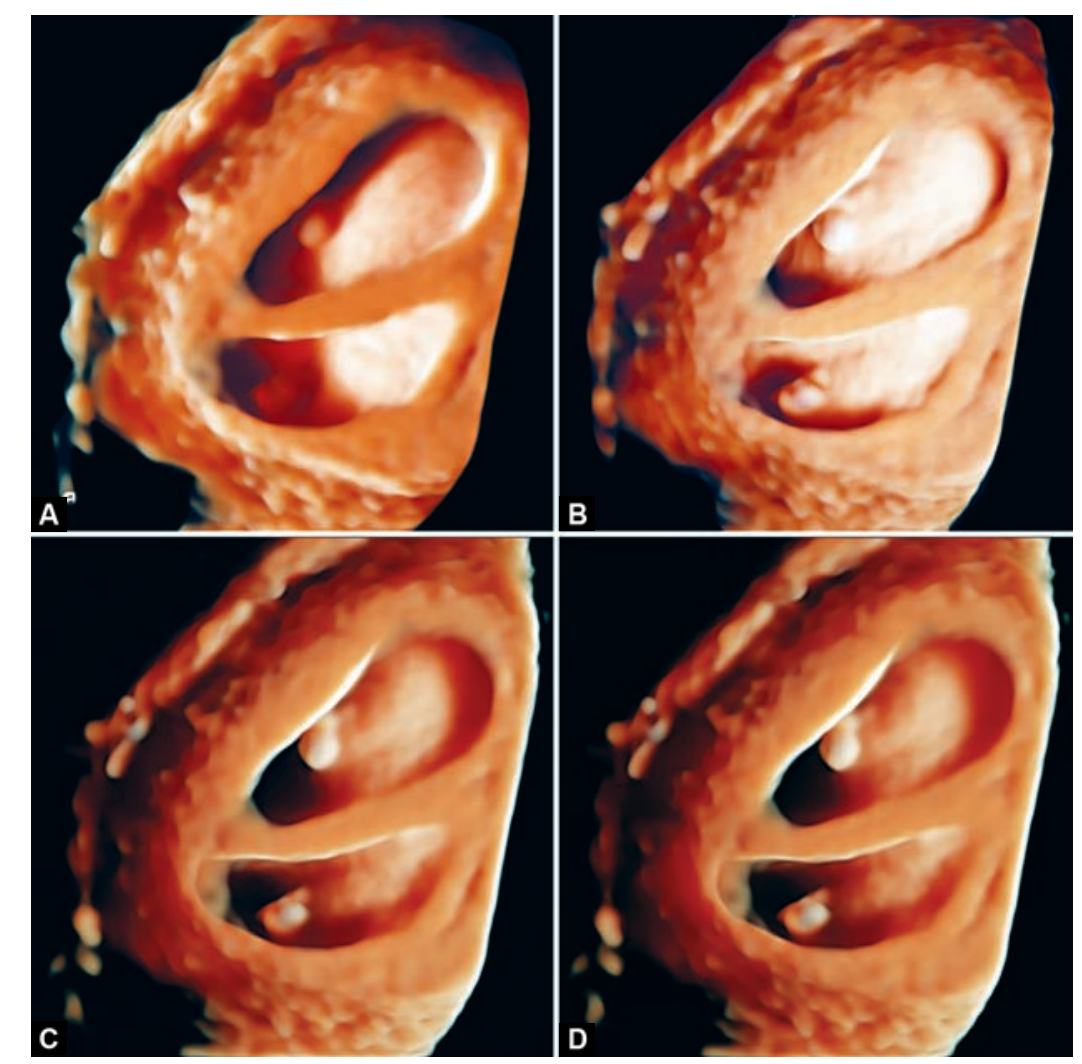

Figs 2A to D: HDlive at 5 weeks of amenorrhea. Twin pregnancy with two distinct yolk sacs is visible 

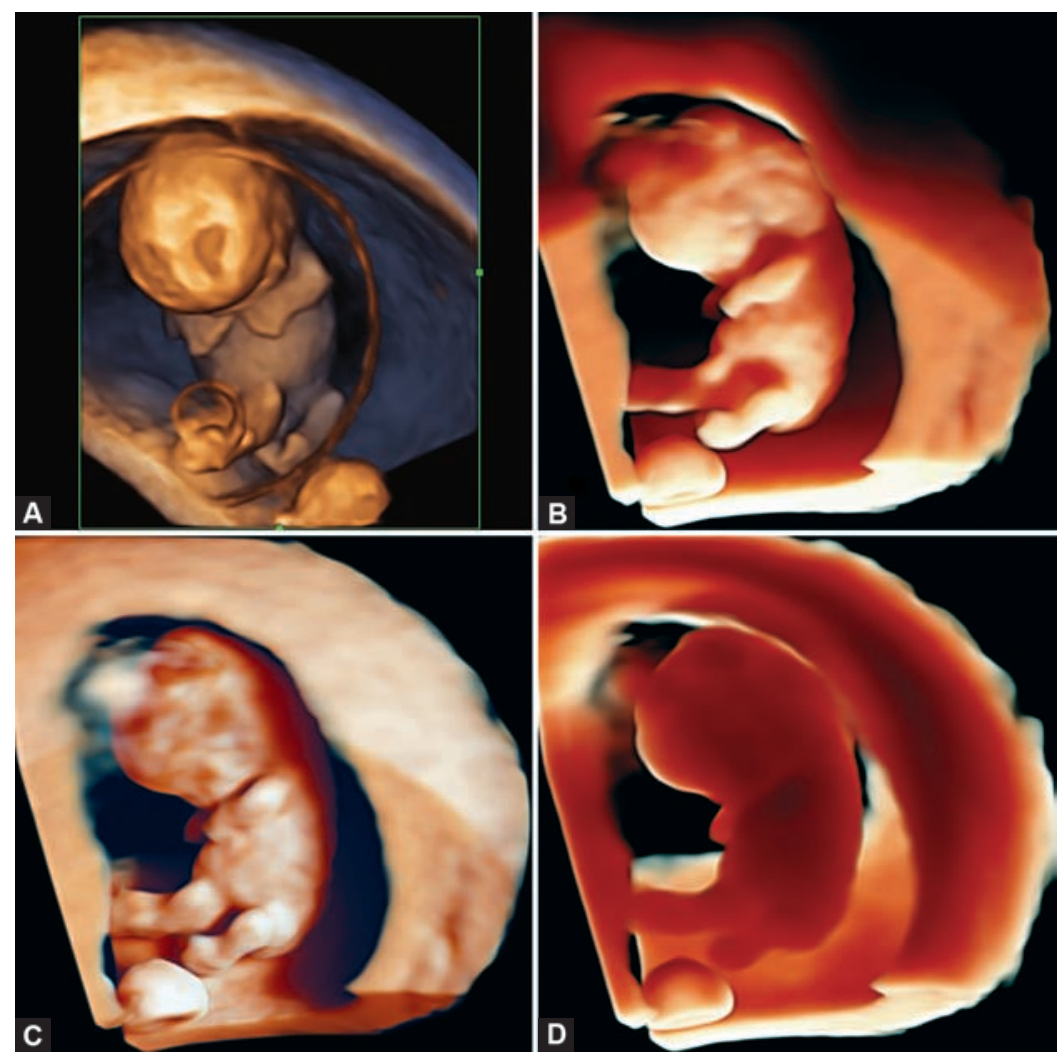

Figs 3A to D: Pregnancy first trimester 9 weeks of amenorrhea. The possibility of changing light is clearly observed

is obtained. ${ }^{10}$ Both $3 \mathrm{D}$ and the realistic pictures of HDlive are important tools in evaluating the facial anatomy of the fetus. Ultrasound evaluation of the fetal face is an important step during obstetrical ultrasound because a detailed facial examination can provide a lot of information alerting the clinician to the possibility of associated anomalies in the fetal anatomy. ${ }^{11,12}$ HDlive and 3D ultrasound have the ability to display a true midsagittal plane of the face. ${ }^{13}$ HDlive not only provides information about face anomalies but also provides more convincing evidence about a normal face, very important information in cases with increased risk of recurrent surface malformations. ${ }^{10}$ Beyond the spectacular beauty of the HDlive images, this technique will probably provide much more information to assess the fetal face (Figs 5A to D).

HDlive is useful not only in face examination but also in examining the surface details. A clear picture of the hands, feet, abdomen, spine, and fetal genital organs can be obtained (Figs 6A and B). ${ }^{7,14}$

A $2 \mathrm{D}$ and $4 \mathrm{D}$ ultrasound are complementary methods used for the evaluation of fetal movements. The introduction of $4 \mathrm{D}$ ultrasound into clinical practice allows better viewing of facial expressions, such as mouth opening, tongue protrusion, yawning, smiling, and eye opening and blinking, to be studied in great detail. The recent development of the advanced technique of 4D sonography and HDlive open a

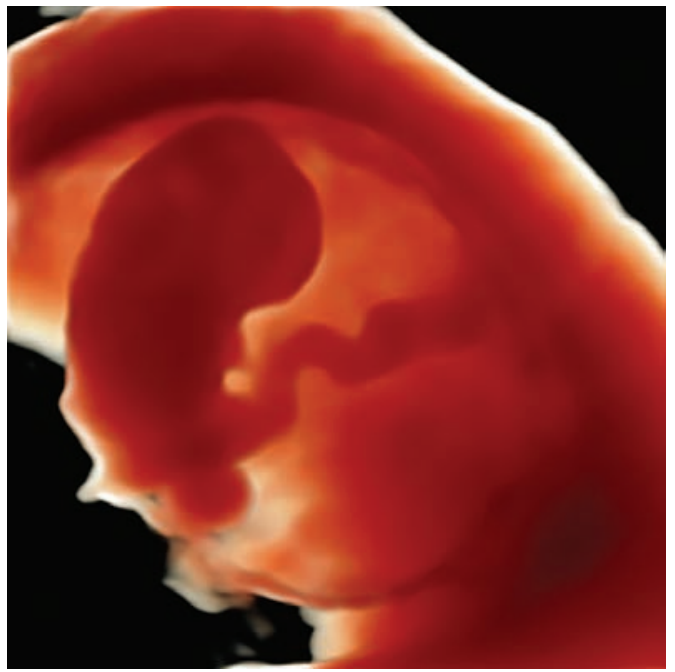

Fig. 4: HDlive at 9 weeks of gestation demonstrating the fetus and the yolk sac; the amnion can be seen as a spherical hyperechoic membrane

new perspective for research into fetal behavior and, particularly, facial movements.

Visualization of the fetus by the mother may arouse emotions capable of triggering or improving maternal-fetal bonding, and that may lead to changes in behavior and lifestyle that promote maternal and fetal health. ${ }^{15}$ Because of the natural appearance of the image with HDlive, the movements of the fetus could have a great impact on the parents. Several studies suggest that patients who are undergoing volume sonography 

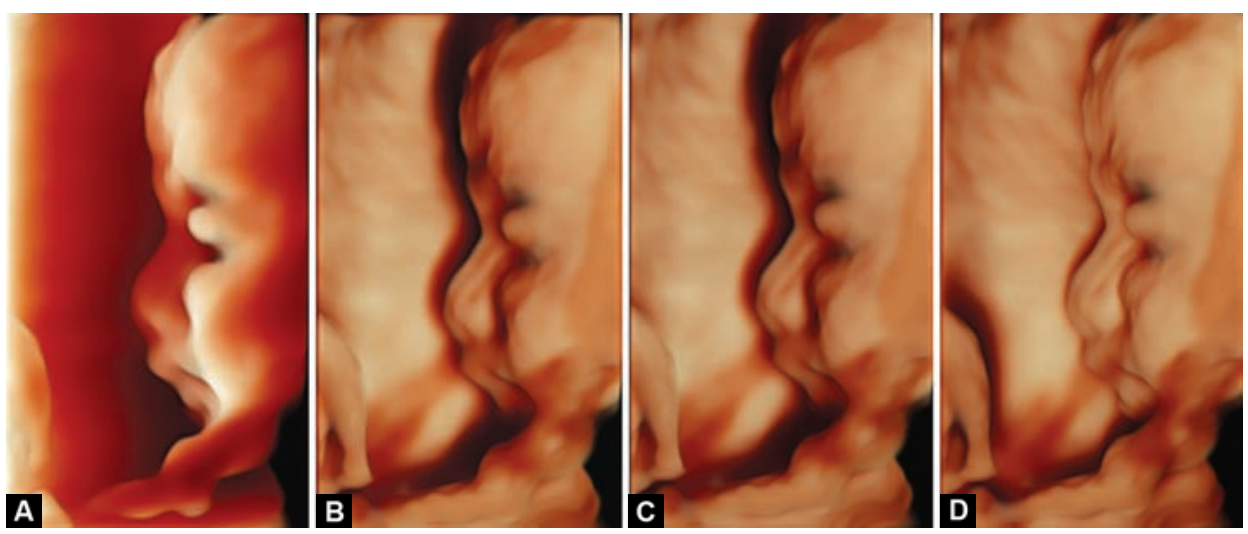

Figs 5A to D: Fetal face-HDlive surface rendering of a fetal face at 33 weeks

and viewing the 3D and 4D images report enhanced bonding with their fetuses and more positive feelings about the experience than do patients having 2D sonography. According to Steiner, ${ }^{16}$ patients more easily recognize 3D images of the fetus than 2D images, and they feel more attached to the fetus after having 3D ultrasound. Ji ultrasound et al compared maternal-fetal bonding between mothers exposed to 2D ultrasound only and to both 2D ultrasound and 3D ultrasound and showed that 3D ultrasound may have had a greater impact on the maternal-fetal bonding process than 2D ultrasound. ${ }^{17}$

In contrast, Rustico ${ }^{18}$ published a study in which the addition of 4D sonography did not significantly change the perception women had of their fetuses compared to 2D ultrasound. Preliminary analyses of a current study that we are performing in our center shows that the role of HDlive should not be neglected. We intend to publish the results of this study in the near future. HDlive images can contribute not only to fetal-maternal bonding but also to physicianpatient bonding with the aid of life-like images. We believe that the impressive images obtained with HDlive offer us the occasion to feel closer to our patients, and we can establish a friendlier professional environment that is useful during the monitoring of the pregnancy.

HDlive was developed especially for obstetric usage because it provides a natural and realistic appearance of the fetus, but its use in gynecology should not be neglected because 3D ultrasound allows unique ways for assessing uterine and adnexal pathology. ${ }^{19,20}$ The main advantage of 3D ultrasound in uterus scanning is the possibility of displacing the coronal plane of the uterus. This plane is particularly important for diagnosing uterine congenital anomalies. Also, $3 \mathrm{D}$ ultrasound is the ideal imaging modality for examining ovarian morphology. Improved delineation of the ovarian lesions provides a more reliable diagnosis. The introduction of 3D Doppler differentiates between high- and low-risk lesions with far greater diagnostic confidence. In ovarian pathology, HDlive could be useful for clearly viewing the
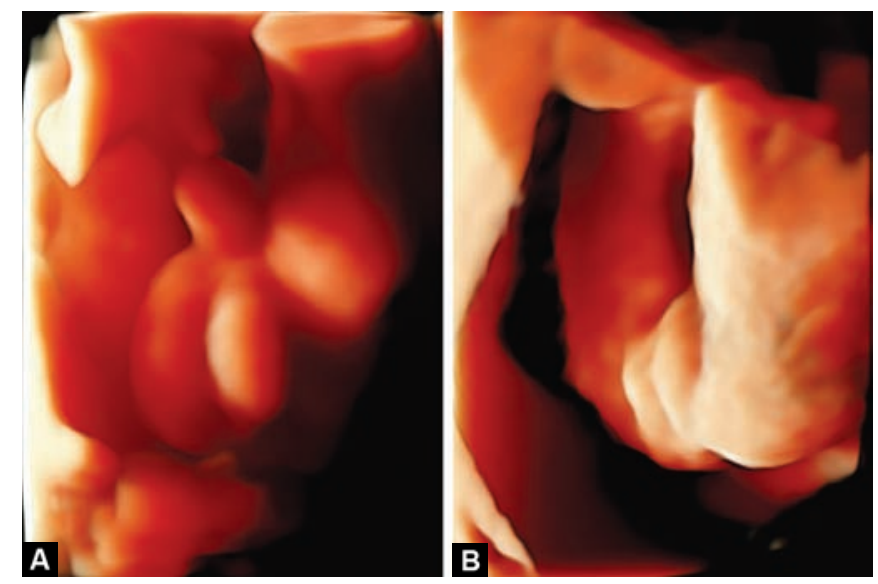

Figs 6A and B: External genital male $(A)$ and female (B) genitalia can be clearly depicted by 3D HDlive

papillary projections within the tumor and the extent of these projections. HDlive enables a complete inspection of the inner surface of the tumor and a clearer evaluation of the papillae and the septum in cases of complex tumoral masses.

\section{CONCLUSION}

HDlive is the latest ultrasound technology that gives us more clear and natural images both in obstetrics and gynecology. Although its advantages need to be further explored, HDlive is an innovative technique and a useful tool for a more realistic visualization of the embryo and the fetus surfaces. Hence, HDlive may help to strengthen the relationship between parents and their child. In gynecology, HDlive can be used both in examining the coronal plane of the uterus and adnexal pathology.

\section{REFERENCES}

1. Mertz E, Pashaj S. Current role of 3D/4D sonography in obstetrics and gynecology. Donald Ultrasound J Ultrasound Obstet Gynecol 2013;7(4):400-408.

2. Benacerraf BR, Benson CB, Abuhamad AZ, et al. Three- and fourdimensional ultrasound in obstetrics and gynecology: proceedings 
of the American Institute of Ultrasound in Medicine Consensus Conference. J Ultrasound Med 2005;24(12):1587-1597.

3. Grigore M, Mares A. The role of HDlive technology in improving the quality of obstetrical images. Med Ultrason 2013;15(3):209-214.

4. Salim R, Woelfer B, Backos M, Regan L, Jurkovic D. Reproducibility of three-dimensional ultrasound diagnosis of congenital uterine anomalies. Ultrasound Obstet Gynecol 2003;21(6): 578-582.

5. Moini A, Mohammadi S, Hosseini R, Eslami B, Ahmadi F. Accuracy of three-dimensional sonography for diagnosis and classification of congenital uterine anomalies. J Ultrasound Med 2013;32(6):923-927.

6. Nebeker J, Nelson R. Imaging of sound speed reflection ultrasound tomography. Journal of Ultrasound in Medicine 2012; 31(9):1389-1404.

7. Bonilla-Musoles F, Raga F, Castillo JC, et al. High definition realtime ultrasound (HDlive) of embryonic and fetal malformations before week 16. Donald School J Ultrasound in Obstetrics and Gynecology 2013;7(1):1-8.

8. Hata T, Aoki S, Manabe A, Hata K, Miyazaki K. Three-dimensional ultrasonography in the first trimester of human pregnancy. Hum Reprod 1997;12:1800-1804.

9. Benoit B, Hafner T, Kurjak A, Kupesic S, Bekavac I, Bozek T. Three-dimensional sonoembryology. J Perinatal Med 2002; 30(1):63-73.

10. Kurjak A, Azumendi G. The fetus in three dimensions-imaging, Embriology, Fetoscopy, Informa Uk Ltd, 2007;181-215.

11. De Mayer V, Zeman W, Palmer CC. The face predicts the brain: diagnostic significance of medial facial anomalies for holoprosenencephaly (archinencephaly). Pediatrics 1964;34(8): 256-258.
12. Rotten D, Levaillant JM. Two- and three-dimensional sonographic assessment of the fetal face. A systematic analysis of the fetal face. Ultrasound Obstet Gynecol 2004;23(3):224-231.

13. Merz E, Weber G, Bahlman F, Miric-Tesanic D. Application of transvaginal and abdominal three-dimensional ultrasound for the detection or exclusion of malformation of the fetal face. Ultrasound Obstet Gynecol 1997;9(4):237-243.

14. Bonilla-Musoles F, Raga F, Osborne NG, set al. Multimodality 3-dimensional volumetric ultrasound in obstetrics and gynecology with an emphasis in HDlive technique. Ultrasound Q 2013;29(3):189-201.

15. Goncalves L, Lee W, Espinoza J, Romero J. Three- and fourdimensional ultrasound in obstetric practice: does it help? J Ultrasound Med 2005;24(12):1599-1624.

16. Steiner H, Gregg AR, Bogner G, Graf AH, Weiner CP, Staudach A. First trimester three-dimensional ultrasound volumetry of the gestational sac. Arch Gynecol Obstet 1994;255(4):165-170.

17. Ji EK, Pretorius DH, Newton R. Effects of ultrasound on maternal-fetal bonding: a comparison of two- and threedimensional imaging. Ultrasound in Obstetrics and Gynecology 2005;25(5):473-477.

18. Rustico MA, Mastromatteo C, Grigio M. Two-dimensional vs two- plus four-dimensional ultrasound in pregnancy and the effect on maternal emotional status: a randomized study. Ultrasound in Obstetrics and Gynecology 2005;25(5):468-472.

19. Grigore M. HDlive pictures of a serous ovarian borderline tumor. Ultrasound Obstet Gynecol 2013;41(5):598-599.

20. Raga F, Castillo JC, Bonilla F Jr, Bonilla-Musoles F. HDlive ultrasound images in assisted reproduction treatment. Reprod Biomed Online 2013;26(3):269-271. 